\title{
Evolutionary History and Population Genetic Structure of Asian Elephants in India
}

\author{
T N C Vidya*
}

(Received 20 October 2015)

\begin{abstract}
The Asian elephant (Elephas maximus), which has shared a long and rich cultural relationship with humans in India, is endangered in the country today, largely because of habitat loss. There are an estimated 41,400-52,300 Asian elephants worldwide, of which over half range in India. I describe studies that examined the evolutionary history of the Asian elephant, uncovering a surprising coexistence of divergent clades of mitochondrial DNA (mtDNA) within the species, often within populations. Several hypotheses were proposed to explain this coexistence of divergent clades, but it required extensive sampling of elephants from India (because of its large populations of elephants), along with samples from other countries, to gain an understanding of Asian elephant phylogeography, which was found to be largely shaped by Pleistocene climatic oscillations. I also describe studies of the genetic variability of the Indian populations based on mtDNA and nuclear microsatellite DNA and discuss reasons for the patterns seen. Examination of population genetic structure within India, and the geographic barriers that gave rise to such structuring are also described. I end with possibilities for future research, such as addressing the possibility of subspecies within the Asian elephant, understanding the low levels of genetic diversity in southern India, and explaining patterns of population genetic differentiation and breaks in gene flow in elephants and other animals in southern and northeastern India.
\end{abstract}

Key words: Asian elephant phylogeography, Fossil record, Pleistocene climatic oscillations, subspecies, Population genetic structure, Palghat Gap

\section{InTRODUCTION}

The Asian elephant (Elephas maximus) shares a long, complex cultural relationship with humans in India (see Sukumar, 2011). It has been revered as a God, extensively symbolised in art and culture, feared for the destruction it can cause, hunted for ivory, and used as a beast of burden, a formidable war machine, and an instrument to clear and, more recently, protect its own habitat.

In the eloquent words of Lorimer (2010),

Asian elephants are companion species par excellence: too social and sagacious to be objects; too strange to be human; too captive to be wild, but too wild to be domesticated...Humans and elephants have co-evolved; they are companions.
The Asian elephant probably ranged across Asia, south of the Tigris-Euphrates river basin in the west to the Yangtze-Kiang in China in the east, and across southeast Asia, about 4,000 years ago (Sukumar, 2003, pp. 45). However, habitat loss reduced the Asian elephant's range to approximately $6 \%$ of its historical range, and this loss of habitat, along with capture in large numbers for taming and warfare, and poaching of males for ivory has resulted in the species' population size in the wild plummeting to an estimated 41,400-52,300 individuals currently (Sukumar, 2003). The species is presently distributed across 13 Asian countries (see Fig. 1): India with an estimated 24,000-29,500 elephants, Nepal,

\footnotetext{
* Evolutionary and Organismal Biology Unit, Jawaharlal Nehru Centre for Advanced Scientific Research (JNCASR), Bengaluru, Email: tncvidya@jncasr.ac.in
} 


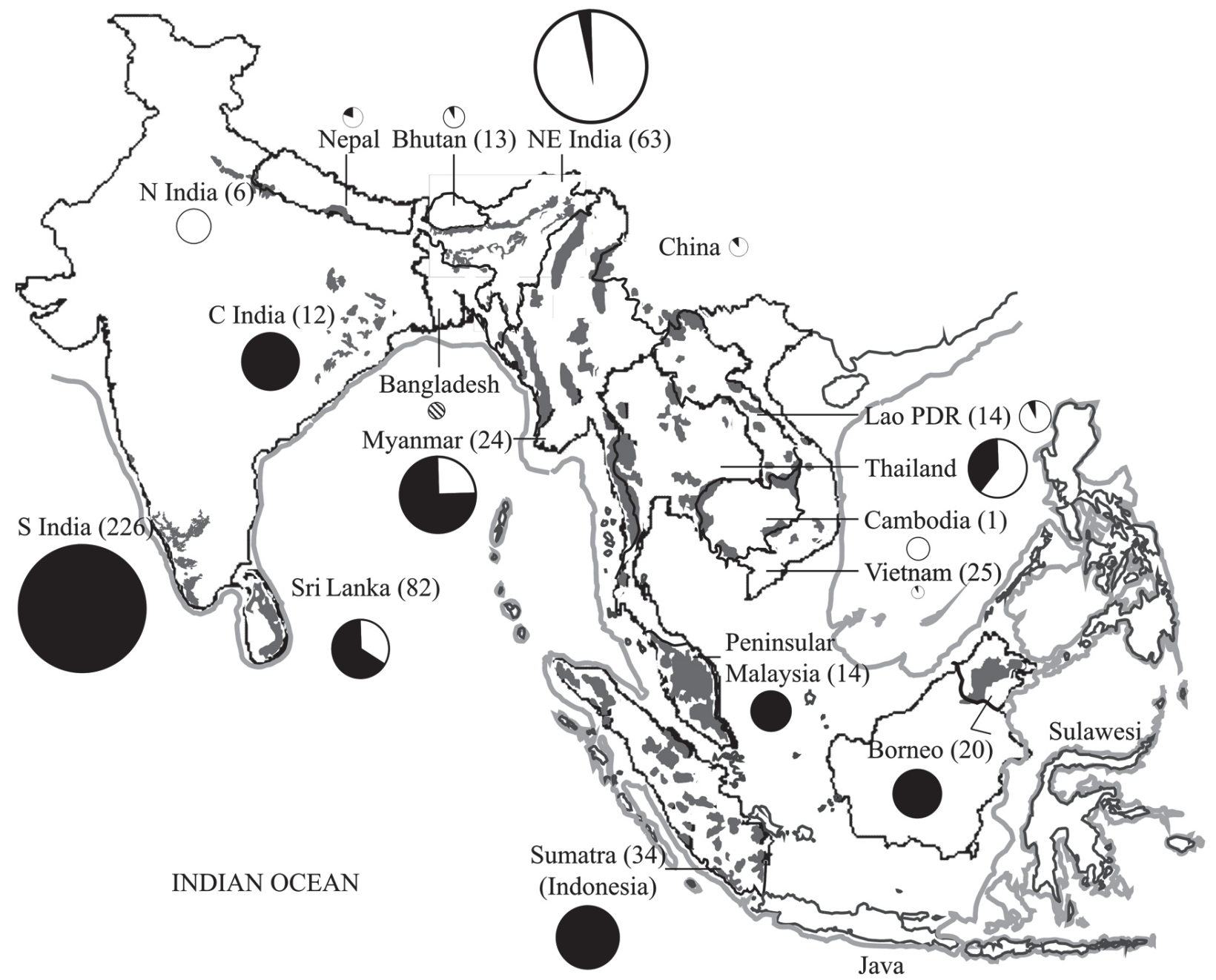

Fig. 1. Map showing current Asian elephant distribution (in dark grey; based on Sukumar, 2003 and, for India, based on Vidya et al., 2005b) and the proportions of $\alpha$ (white in pie-charts) and $\beta$ (black in pie-charts) clade haplotypes in different populations, largely based on Vidya, et al. (2009). Approximate country borders are shown in black lines and the land-sea boundary during the last glacial maximum (based on Adams and Faure 1997 and Gathorne-Hardy et al., 2002) is shown in light grey lines. The sizes of the pie-charts are proportional to the population sizes in the corresponding populations. The sample sizes used in Vidya et al. (2009) are shown within parentheses after the population name. Pie-charts for Nepal and Thailand are based on Fleischer et al. (2001) and that for China is based on data from Yang and Zhang (2012). The circle for Bangladesh only indicates population size as data for this country are not published.

Bhutan, and Bangladesh, with transboundary populations shared with India totalling approximately 600 elephants, Sri Lanka with 2,500-4,000 elephants, China with approximately 220 elephants in the extreme south of the Yunnan province, Thailand with a rough estimate of 2,5003,200 elephants, Myanmar with an estimated population size of 4,000-5,000 elephants, Laos with a rough estimate of 500-1,000 elephants, Vietnam with 70-150 elephants, Cambodia with approximately 250-600 elephants, Malaysia with probably 1,000-1,500 elephants in peninsular Malaysia and fewer than 1,600 elephants in Borneo, and Indonesia with 2,400-3,400 elephants distributed in numerous small populations (based on Sukumar and Santiapillai, 1996; Bist, 2002; 
Sukumar, 2003). Within India, the elephant probably ranged across the entire country, with the exception of the northern most region of Kashmir, until the sixth century BC (Sukumar, 1989, p.2), and presently about $15 \%$ of this former range remains.

Historically, there has been a great deal of interest in scrutinizing and classifying elephants in India by morphology. The ancient Sanskrit texts, Gaja-śāstra (by Pālakāpya), Arthaśāstra (by Kautilīya), and Mātanga-līlā (by Nilakantha) describe morphological variation amongst elephants and point to three or four castes, the stately Koomeriah, the slow or weak Manda, the lanky and nervous Meerga, and a mixed Miśra (or Dvásala in the three caste system with the other two castes being the Koomeriah and Meerga) (see Edgerton, 1985). Sanderson (1879), while acknowledging these differences, noted that these types could be found within herds and were, therefore, not hereditary. Deraniyagala (1955), however, claimed that entire herds must show certain variations as there were Indian mahouts who were confident of identifying the natal districts of elephants based on their morphology. Deraniyagala (1955) himself recognized 14 subspecies of Asian elephant, of which one was a fossil species and four or five were thought to have recently gone extinct. A few decades after this (Deraniyagala's) work, the endangered status of the Asian elephant, along with the advent of molecular techniques, led to attempts by scientists to assess genetic diversity and identify subspecies for conservation. These naturally led to studies on the evolutionary history and population genetic structure of the species. Here, I trace these studies, carried out during the last decade and a half, and give an overview of Asian elephant phylogeography across its range, and its genetic diversity and population genetic structure in India.

\section{The Fossil Record}

Based on the fossil record, the genus Elephas (Family Elephantidae) appeared to have originated by the early Pliocene, over 5 million years ago (Mya), in Africa (Maglio, 1973). A more recent study using molecular data, however, pushed the divergence between the Loxodonta (the genus including the present-day African elephants) and Elephas lineages even further back, at 7.6 (95\% CI 6.6-8.8) million years ago (Mya) (Rohland et al., 2007). Elephas ekorensis is the earliest known species of its genus and was found in Africa (Maglio, 1973). A derivative of Elephas ekorensis - Elephas recki complex is thought to have colonized Asia and given rise to Elephas planifrons (found in the Siwalik Hills ca.3.6 Mya) and Elephas hysudricus (found in the Siwalik Hills ca. 2.7 Mya and other areas, see Fig. 2) (Maglio, 1973; see Nanda, 2002). Another derivative of $E$. recki, E. namadicus, subsequently colonized Asia, late in the Early Pleistocene, and displaced the previous species over a large part of their ranges. However, E. namadicus went extinct in the Late Pleistocene and E. hysudricus appears to have given rise to E. maximus, the Asian elephant, in southern Asia ca. $0.25 \mathrm{Mya}$, and to $E$. hysudrindicus on Java ca. 0.8-1.0 Mya (Maglio, 1973; Van den Bergh et al., 1996). A spate of extinctions at the end of the Pleistocene, about 10,000 years ago, left E. maximus as the lone surviving proboscidean on the Asian continent.

\section{Initial Molecular Genetic Studies on the Asian Elephant}

The earliest studies of genetic variation and differentiation in Asian elephants were carried out by Nozawa and Shotake (1990) and Hartl et al. (1995), who sampled 20 and 17 captive animals, respectively, of Indian origin, and examined electrophoretic variation in blood proteins and enzymes from these samples. Both studies found low electrophoretic variation. A major finding of Nozawa and Shotake's (1990) study was significant differentiation between the mainland and Sri Lankan populations, supporting the idea of distinct subspecies. At the time, three subspecies, E. maximus maximus (the Sri Lankan 


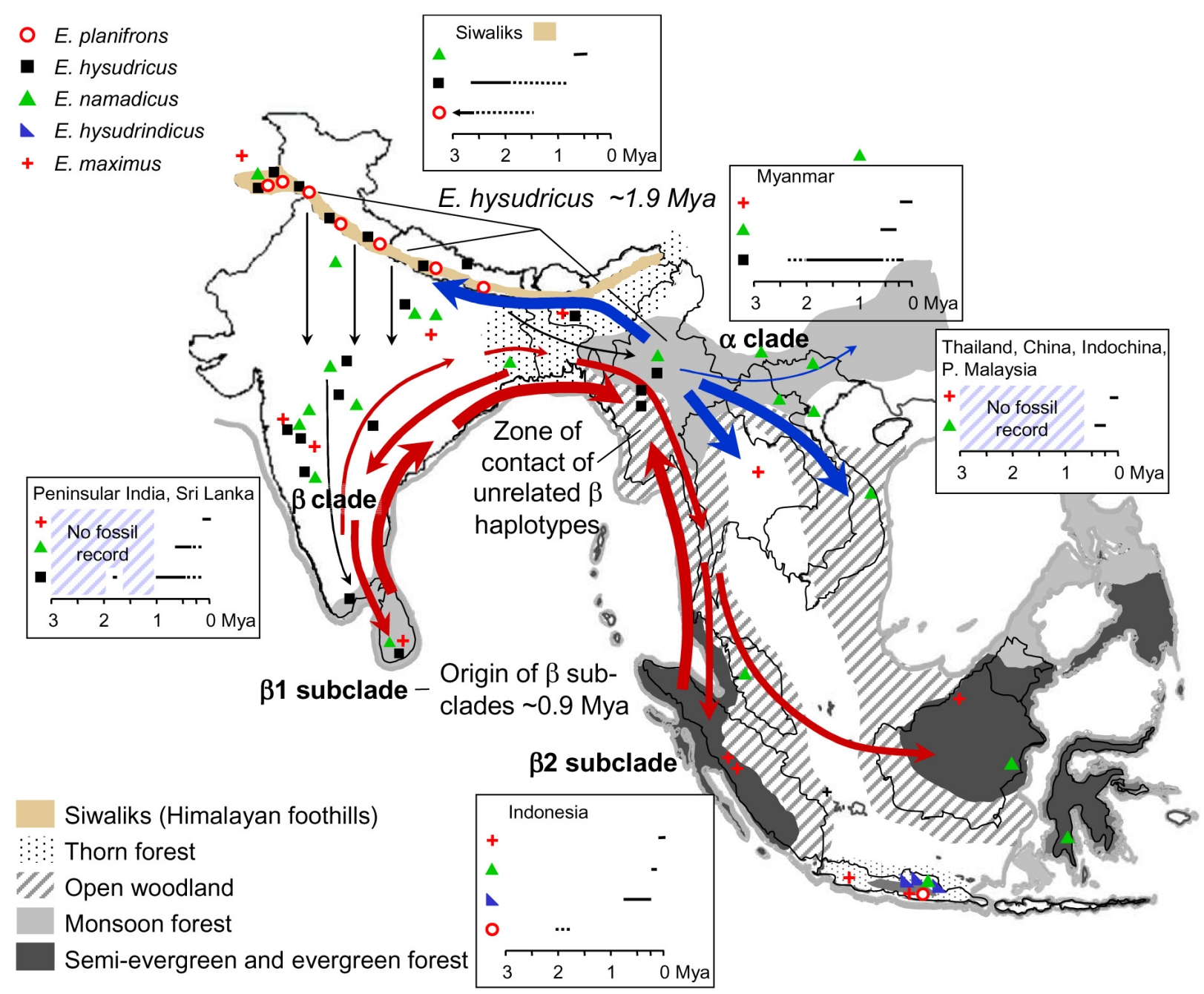

Fig. 2. Fossil distribution of Elephas species in south and southeast Asia (dotted lines indicate fossils that are rare or of doubtful age) and a schematic of the sequence of events proposed to explain current distribution patterns of Asian elephant mitochondrial haplotypes, both based on Vidya et al. (2009). Recent movements are shown by arrows of increasing thickness. Arrows indicating $\alpha$ clade movement are in blue, those indicating $\beta$ clade movement are in maroon, and those preceding the formation of the two clades are in black. Southward migration and the resulting allopatric fragmentation resulted in the formation of the two clades ca. 1.9 Mya. Subsequent southward migrations, at least 0.9 Mya, and isolation of populations resulted in the origin of the $\beta 1$ and $\beta 2$ subclades. Northward expansions of these subclades gave rise to a zone of contact of unrelated $\beta$ clade haplotypes in Myanmar, and outward expansions of the $\alpha$ clade gave rise to populations with both divergent clades coexisting. The base map shows palaeovegetation types and land-sea boundary during the last glacial maximum based on Adams and Faure (1997) and Gathorne-Hardy et al. (2002). Monsoon forests and semi-evergreen and evergreen forests possibly served as Pleistocene glacial refugia.

elephant), E. maximus indicus (the Indian elephant), and E. maximus sumatranus (the Sumatran elephant) were recognized by Shoshani and Eisenberg (1982) based on morphology. The first study to examine the phylogeography of Asian elephants using DNA-based data was carried out by Hartl et al. (1996). Hartl et al. (1996) examined variation in 335 base pairs (bp) of the mitochondrial cytochrome $b$ gene across 53 captive elephants, believed to have originated from Sri Lanka, southern India, northeastern India and northern Myanmar, southern Myanmar and 
northern Thailand, and eastern Thailand and Vietnam. The sample sizes from these populations were (understandably) small, with no population being represented by more than 14 individuals, and southern India and northeastern India-northern Myanmar (the two largest populations of Asian elephants in the world) being represented by only nine and 11 individuals, respectively. However, even this small sample showed the presence of eight mtDNA haplotypes, which clustered into two distinct clades (Hartl et al., 1996). There was no major genetic differentiation of Sri Lanka from the mainland, with both regions showing haplotypes of both clades. It was, therefore, inferred that Sri Lankan and Indian elephants did not represent different subspecies. Since several haplotypes were found to exhibit disjunct distributions, Hartl et al. (1996) also suggested that these haplotypes may have already been present when the elephant colonized southern and southeastern Asia during the Pliocene, and their frequencies may have been altered through genetic drift when population sizes were impacted by humans.

Fernando et al. (2000) carried out a more detailed analysis of genetic structure of elephants in Sri Lanka, largely sampling free-ranging elephants (using dung as the source of DNA in one of the first such studies using non-invasive sampling), and compared Sri Lankan elephants with those from Bhutan-northeastern India $(n=19)$ and Laos-Vietnam $(n=18)$. Based on a 630-bp segment of mtDNA, which included the Cterminal of cytochrome $b$, sequences for proline and threonine tRNAs, and part of the variable left domain of the control region, high diversity of haplotypes was found in Sri Lanka, and significant genetic differentiation was observed between Sri Lanka and the mainland. The two distinct clades of haplotypes were observed again and called the $\alpha$ and $\beta$ clades, corresponding to the B and $A$ clades, respectively, of Hartl et al. (1996). Fernando et al. (2000) explained their observed distribution by invoking allopatric divergence of the mainland and the Sri Lankan populations during the Pliocene, followed by secondary admixture during the Pleistocene, when there was repeated emergence of a land bridge between Sri Lanka and India. Introgression of mtDNA from a closely related species, possibly E. namadicus, to E. maximus was also discussed, and dismissed, as a possibility, in conjunction with allopatric divergence, in order to explain the coexistence of the two divergent clades.

In a study published soon after that of Fernando et al. (2000), Fleischer et al. (2001) sampled 57 captive elephants originating from northeastern India $(n=4)$, Nepal $(n=5)$, Myanmar $(n=4)$, Thailand $(n=14)$, Malaysia $(n=7)$, Indonesia $(n=8)$, and Sri Lanka $(n=15)$, and found that although haplotypes from both divergent clades co-occurred in most populations, only haplotypes from a subclade of the $\beta$ (or A) clade were found in Indonesia and Malaysia, prompting a call for this population to be treated as a separate Evolutionarily Significant Unit (ESU, see Ryder, 1986). This study was based on almost the same mtDNA segment as that used in Fernando et al.'s (2000) study. The coexistence of the two divergent clades was hypothesized to have arisen either through lineage retention (the phenomenon of mitochondrial lineages not having gone extinct stochastically through lack of daughters in a lineage, because of large enough population size) or, more probably, because of recent admixture of two allopatric populations. It was surmised that the $\beta$ (or A) clade had originated in $E$. hysudrindicus, found in the Sunda region, the $\alpha$ (or B) clade had originated in E. maximus (or in its progenitor, E. hysudricus), and the admixture of the two clades had ensued from dispersal events possibly initiated by the volcanic eruption of Toba $\sim 710,000$ years ago. Extensive trade in elephants between southern India, Sri Lanka, and Pegu in southern Myanmar was invoked to explain the high proportion of $\beta$ (or $\mathrm{A}$ ) clade haplotypes in southern India and Sri Lanka (as found by Hartl et al., 1996 and Fernando et al., 2000). 
A shortcoming with these studies was the small number of samples from India, moreover from captive elephants, which could change ownership in captivity, obfuscating the provenance of such animals. Therefore, a wide sampling of free-ranging elephants from various populations in India was required to obtain a more realistic picture of the distribution of the two clades, and test hypotheses relating to their coexistence. A series of studies that subsequently carried out such sampling are described below.

\section{Mitochondrial haplotype Diversity WITHIN INDIA AND A RE-EXAMINATION OF THE HYPOTHESES RELATING TO THE COEXISTENCE OF THE $\boldsymbol{\alpha}$ AND $\boldsymbol{\beta}$ CLADES}

Vidya et al. (2005a,b) non-invasively sampled 297 free-ranging elephants and 29 captive elephants (whose natal populations were known) from the four regions that harbour elephants in India, southern (along the Western and Eastern Ghats), central, northern (along the northwestern Himalayan foothills), and northeastern (along the northeastern Himalayan foothills) India. Southern India is home to three large elephant populations, from north to south along the Western Ghats, the Nilgiris-Eastern Ghats and Nilambur - Silent Valley - Coimbatore population (together called the Nilgiris population henceforth), which is the single largest population of Asian elephants in the world (with 9,000 elephants), the AnamalaiParambikulam (henceforth, Anamalai) population (with 1,500-2,700 elephants), and the PeriyarKalakkad Mundanthurai (henceforth, Periyar) population (with $\sim 1,500-2,500$ elephants) (see Vidya et al. 2005b). The Nilgiris population is separated from the more southerly populations by the $40-\mathrm{km}$ wide Palghat Gap, which is the only complete discontinuity in the Western Ghats. Northeastern India also holds three large populations, the North Bank population (with $\sim 3,000$ elephants) to the north of the Brahmaputra river, the Eastern Region population (with $\sim 1,000$ elephants) in the eastern areas of the south bank of the Brahmaputra, and the SouthwestSouthcentral Bank population (with 5,500 elephants) in the central and western areas of the south bank of the Brahmaputra (see Vidya et al., 2005b). Central India harbours an estimated 2,4002,700 elephants in several fragmented forests, and northern India harbours a relict population of approximately 900-1,000 animals (see Vidya et al., 2005b).

Examining the same segment of mtDNA as that used by Fernando et al., (2000), Vidya et al., (2005b) found a total of eight mtDNA haplotypes across elephant populations in India: five of these were found in southern India, two in central India, a single haplotype in northern India, and three in northeastern India. The haplotypes from southern and central India belonged to the $\beta$ clade, that from northern India was from the $\alpha$ clade, and those from northeastern India were from both, although largely the $\alpha$, clades (Vidya, et al. $2005 b)$. The preponderance of $\beta$ clade haplotypes in southern and central India was not compatible with the hypothesis that trade in elephants had transported this clade to Sri Lanka and India from southeast Asia (Vidya, et al. 2005a).

Combining data from these Indian samples along with data from new samples from Vietnam, Sumatra, Malaysia, and Myanmar, and previously published data from other countries, Vidya et al., (2009) re-examined hypotheses relating to the coexistence of the two mtDNA clades. Phylogenetic analyses (using maximum parsimony, minimum evolution, and Bayesian approaches) revealed a clear distinction between the two clades. Based on previously estimated divergence times between Loxodonta and Mammuthus-Elephas lineages (7.24-8.01 Mya, mean=7.63 Mya) and between Mammuthus and Elephas (6.29-7.07 Mya, mean=6.68 Mya) (Rohland et al., 2007), the divergence time between the $\alpha$ and $\beta$ clades was estimated at 1.88 Mya (CI 1.80-1.95 Mya, cytochrome $b$ based 
divergence time 1.6-2.1 Mya) (Vidya et al. 2009). This divergence time between the two clades precluded introgression from $E$. namadicus into E. hysudricus (progenitor of E. maximus) (divergence time of over $5 \mathrm{My}$ ) and from $E$. hysudrindicus into E. maximus (divergence time of $0.8-1 \mathrm{My}$ ) as the raison d'etre for the coexistence of the two clades in E. maximus. Additional structure within the $\beta$ clade was also found, with support for a $\beta 1$ and a $\beta 2$ (probably corresponding to the Sumatran subclade of Fleischer et al. 2001) subclades. Reconstruction of the ancestral areas of origin of the clades through a dispersal-vicariance analysis (Ronquist 1996) uncovered Sri Lanka and Sumatra as the probable areas of origin of the $\beta 1$ and $\beta 2$, subclades, respectively, and Myanmar as the probable area of origin of the $\alpha$ clade (Vidya et al., 2009, see Fig. 2).

Both $\alpha$ and $\beta$ clades were found to have undergone bottlenecks when mismatch distributions were analyzed, with the mean times of expansion of the $\alpha$ and $\beta$ clades being of the order of a few hundred thousand years ago and close to a million years ago, respectively (Vidya et al. 2011). The upper limits of female population sizes prior to these expansions were estimated to be 4,380 and 9,615, respectively, in the $\alpha$ and $\beta$ clades, based on a $1.6 \mathrm{My}$ divergence between the clades, and 5,841 and 12,820, respectively, based on a 2.1 My divergence between the clades. These numbers were much smaller than the 17,500 or 30,700 females (based on 1.6 My and 2.1 My, divergences between the clades, respectively) that should have existed for the two clades to have arisen in a single population through lineage retention, thus rejecting the lineage retention hypothesis for clade coexistence in the Asian elephant (see Vidya et al., 2009, 2011).

A nested clade analysis was also carried out by Vidya et al. (2009), in order to examine whether there were geographic associations of haplotypes and, if so, whether these associations arose from restricted gene flow, range fragmentation, or range expansion/long-distance colonization (Templeton, 1998, 2004). The $\alpha$ and $\beta$ clades were organized into a set of nested clades (not to be confused with the $\alpha$ and $\beta$ clades themselves) in this analysis following certain rules. The analysis revealed strong geographic associations of haplotypes. Restricted gene flow and contiguous range expansion were uncovered in the $\alpha$ clade. In the $\beta$ clade, restricted gene flow was inferred in two clades that were subsets of the $\beta 1$ and $\beta 2$ subclades, respectively, indicating that these clades arose in isolation in Sri Lanka and the Sunda region, respectively. The nested clade (more inclusive clade) of these two clades was distributed across the Sunda region, Sri Lanka, and Myanmar, and revealed past fragmentation, followed by range expansion. Together with the inference of a zone of secondary contact of unrelated $\beta$ clade haplotypes in Myanmar, this suggested that the $\beta$ clade had become isolated in Sri Lanka and the Sunda region, where they had diverged into the $\beta 1$ and $\beta 2$ subclades, and had subsequently expanded northwards from these areas (Vidya et al., 2009).

The phylogenetic and phylogeographic analyses of Vidya et al. (2009), along with the fossil record and the timing of the Pleistocene initiation in India ( $1.9 \mathrm{Mya})$, suggested that both the $\alpha$ and $\beta$ clades had originated in E. hysudricus itself. The fossil record (see Figure 2) had suggested a southward movement of E. hysudricus from the Siwaliks with the advent of the Pleistocene, in response to the cold climate and increasing tectonic activity in the Himalayas. Fragmented into two populations in different glacial refugia, possibly in southern India-Sri Lanka and in the Irrawadies of Myanmar, the $\alpha$ and $\beta$ clades were thought to have arisen in allopatry (Vidya et al., 2009). During a later glacial period, $\beta$ clade haplotypes that had expanded northwards from southern India-Sri Lanka during a warm period might have been forced southwards 
again, becoming isolated in both Sri Lanka and in the Sunda region, giving rise to the $\beta 1$ and $\beta 2$ subclades (Vidya et al., 2009, see Fig. 2). Expansions during subsequent warm interglacial periods might have then resulted in the coexistence of both $\beta$ subclades in Myanmar, and both $\alpha$ and $\beta$ clades in several populations, albeit with some clinality ( $\alpha$ clade with a more northerly distribution than the $\beta$ clade, see Figure 1) because of the areas of origin of the two clades (Vidya et al., 2009). This study showed that repeated climatic oscillations during the Pleistocene had probably played an important role in shaping the phylogeography of the species rather than mitochondrial introgression between species, lineage retention, or large-scale trade in elephants. It is, however, conceivable that the $\alpha$ clade was brought to Sri Lanka through trade in elephants from Myanmar, because of the similarity of $\alpha$ clade haplotypes between the two countries and absence of the $\alpha$ clade in the intervening populations (Vidya et al., 2009).

The analysis of Vidya et al. (2009) also supported the absence of subspecies differences between Sri Lanka and the mainland. However, it is necessary to assess differentiation at nuclear genes before determining subspecies status. Nozawa and Shotake (1990) estimated a divergence time of about 100,000 years between the Sri Lankan and Indian elephants based on blood protein variation, which the analysis of Vidya et al. (2009) would not preclude. A Sumatran subspecies was supported by the work of Fleischer et al. (2001) and also, to some extent, by Fernando et al. (2003) and Vidya et al. (2009).

\section{Genetic diversity WITHIN INDIA}

As mentioned above, Vidya et al. (2005b) found eight mtDNA haplotypes of both mtDNA clades within elephants in India. The distributions of the two clades ( $\beta$ clade in southern, central, and northeastern India, and $\alpha$ clade in northern and northeastern India) could be explained by the postulated evolutionary history of the Asian elephant as described above. However, the diversity of mitochondrial haplotypes within India was low compared to those in other populations. Sri Lanka and Myanmar had the highest mitochondrial diversities, whereas the Nilgiris population in southern India, which is the world's single largest population of Asian elephants had no mitochondrial haplotype diversity (Vidya et al., 2005a, 2009, see Table 1). One would expect populations in and near glacial refugia to have the highest diversities, as in the case of Sri Lanka, Myanmar, Sumatra, and Vietnam. Sri Lanka had been found to harbour high diversity even based on a much smaller sample size by Hartl et al. (1996). Northeastern India-Bhutan and Indochina did not have low diversities. Central India also did not show unexpectedly low diversity, given its geographic location and the fact that the population is highly fragmented at present. However, southern India with the largest Asian elephant populations and proximity to Sri Lanka had surprisingly low haplotype diversity (Table 1). Even considered as a whole, southern India harboured only five haplotypes (as opposed to Sri Lanka's 12) and had a haplotype diversity of 0.436 +0.029 . All these haplotypes belonged to the $\beta$ clade despite extensive sampling (Vidya et al., 2005a). It must be mentioned here that Hartl et al. (1996) had found both mitochondrial clades in southern India, with two of the nine haplotypes in southern India belonging to the $\alpha$ clade. However, the elephants sampled in Hartl et al. 's (1996) study had been captive elephants from the state of Kerala, and the origins of these elephants may be difficult to ascertain unambiguously, in the context of captive elephants in Kerala frequently being captured and transported from northeastern India. In a more recent study, Lei et al. (2012) sampled 201 captive Asian elephants from North America, of which 31 were thought to be of Indian origin. Eleven haplotypes were recovered from these 31 animals based on the same mtDNA segment used in the previous studies. Three of these haplotypes 
(all from the $\alpha$ clade) had not been described in any previous study and seven ( $5 \alpha$ clade and $2 \beta$ clade) of the 11 haplotypes were previously unknown from India. This suggests that haplotype diversity in India may not have been very low, at least during the period when these elephants had been captured, if they were indeed from India. The provenance of these sampled elephants within India is not known, but I venture a guess that many of them were from northeastern India, which has been a traditional area of elephant capture (see Sanderson, 1879; Sukumar, 2011 pp. 225-226) and an area with an alarming loss of elephant habitat.

Vidya et al. (2005b) also genotyped 259 elephants from India (212 from southern India, 12 from central India, 6 from northern India, and 65 from northeastern India) at six nuclear microsatellite loci (EMX 1-4, LafMS02, and LafMS03). Low diversity (allelic richness) was found based on the tri- and tetra-nucleotide repeat loci, EMX 1-4, whereas moderate diversity was found based on the dinucleotide repeat loci, LafMS02 and LafMS03, in all the Indian populations, corrected for the number of individuals sampled. The Anamalai and Periyar populations had higher allelic richness (average of 2.88 and 2.86 alleles per locus, respectively) than the Nilgiris population (average of 2.78 alleles per locus), but the differences, although significant, were small (Vidya et al., 2005b). The number of alleles per locus in southern India (mean $+\mathrm{SE}=3.4+0.67$; EMX 1-4 and LafMS03 used) was comparable to those in several other range countries (Table 1), albeit based on small sample sizes (6-20 individuals from each population), and the heterozygosity in southern India was amongst the highest (Fernando et al., 2003).

It is puzzling why mitochondrial diversity in southern India is low whereas nuclear diversity, admittedly based on a small number of loci, is comparable with those in other populations. This pattern cannot be explained by lineage retention because of the larger population sizes in southern
India compared to many other regions, but may have arisen from population bottlenecks. Vidya et al. (2005a) carried out tests to detect recent population bottlenecks using data from microsatellite loci but found no strong evidence of recent bottlenecks. It is possible, however, that there was an ancient population bottleneck, which affected mtDNA to a greater extent than nuclear DNA because of the differences in effective population sizes (mtDNA has only one fourth the effective population size as nuclear DNA as the former is haploid and maternally inherited), and from which the microsatellite loci have recovered but not the mitochondrial haplotypes because of their slower mutation rate (Vidya et al., 2005a). Such a bottleneck is plausible during a glacial period that was more recent than the ones that facilitated the origin of the mitochondrial clades and subclades, for instance, during a period of intense aridity in the Nilgiris about 45,000 years ago or 18,000 years ago (the Last Glacial Maximum) (Sukumar et al. 1993). The more southerly populations, Anamalai and Periyar, may not have been as badly affected as the Nilgiris during such a glacial period.

\section{Genetic STructure Within India}

Vidya et al. (2005a,b) examined population genetic structuring of elephants within India based on the mitochondrial and nuclear microsatellite DNA loci mentioned above. An Analysis of Molecular Variance (AMOVA) using mtDNA revealed hierarchical structuring at the level of regions $(60.6 \%$ of the genetic variation due to differences among the four regions of the country), populations within regions (36.4\% of the variation due to populations within regions, viz., southern and northeastern India), and within populations ( $3 \%$ of the variation) (Vidya et al., $2005 \mathrm{~b})$. Such hierarchical structuring was observed based on microsatellite DNA also, but a large percentage of the total variation was within populations $(86.5 \%)$ instead of between regions 


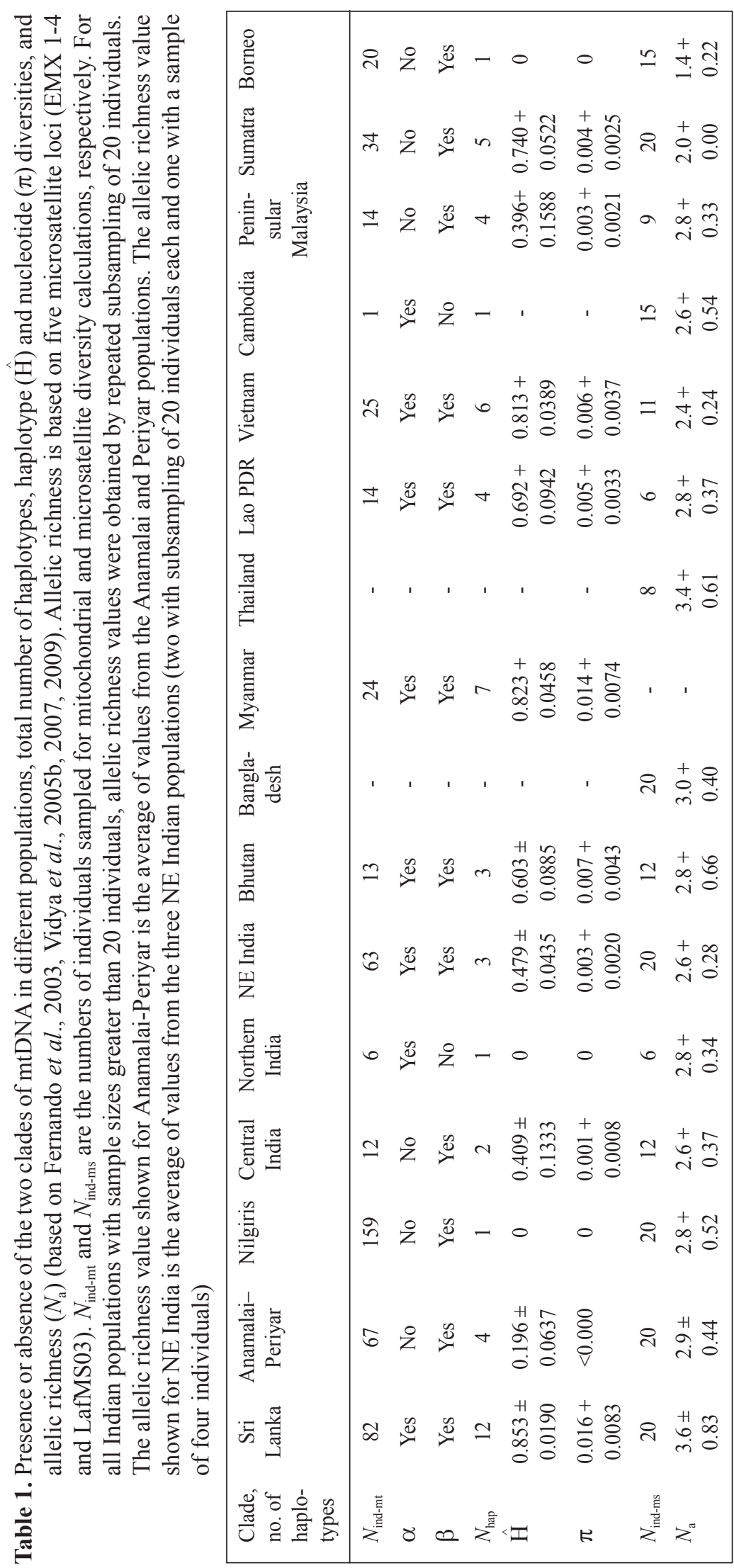


(9.4\%). Pairwise estimates of population genetic differentiation (using $\mathrm{F}_{\mathrm{ST}}$ ) based on mtDNA showed that each of the southern Indian populations was significantly differentiated from the central Indian, northern Indian, and each of the northeastern Indian populations. Central India was significantly differentiated from the northern Indian and each of the northeastern Indian populations, but the northern Indian population was not significantly differentiated from the northeastern Indian populations (Vidya et al., 2005b). A nearly identical pattern of population genetic differentiation was also found based on microsatellite DNA(Vidya et al., 2005b). Pairwise comparisons of populations within southern India has revealed significant genetic differentiation between the Nilgiris population and the more southerly Anamalai and Periyar populations based on both mitochondrial and microsatellite DNA, but no differentiation between the Anamalai and Periyar populations based on either kind of marker (Vidya et al., 2005a). Within northeastern India, there seems to be significant genetic differentiation between the North Bank (of the Brahmaputra) population and the Southwest-Southcentral Bank population based on mtDNA but not based on microsatellite DNA (Vidya et al., 2005b). These results prompted Vidya et al., (2005b) to suggest four Management Units (Moritz, 1994) for elephants in India: Nilgiris, Anamalai-Periyar, central India, and northern-northeastern India. Translocations across these populations were not advised until there was information on the adaptedness of these populations to local conditions.

Pursuing the finding of significant genetic differentiation between the Nilgiris and the more southerly populations at mitochondrial and microsatellite DNA, Vidya et al., (2005a) also carried out tests to detect isolation by distance and breaks in gene flow (across several locations, in an East-West direction within the Nilgiris, and in a North-South direction across populations). No isolation by distance was detected within the Nilgiris population, nor was significant genetic differentiation found between locations within the Nilgiris (significant $\mathrm{F}_{\mathrm{ST}} \mathrm{S}$ only involving two locations at the southern end of the Nilgiris population), which spans almost $15,000 \mathrm{~km}^{2}$. However, although there was no break in gene flow in an East-West direction across the Nilgiris, a significant break in gene flow was uncovered in the North-South transect, corresponding to the Palghat Gap between the Nilgiris and Anamalai (Vidya et al., 2005a). This was the first discovery of the gap being a possible biogeographic barrier to any large mammal (alternate subspecies distributions of a few birds and plants on either side of the gap had been described previously), and a surprising finding in light of the small length of the gap compared to the distances between sampling locations within the Nilgiris (see Vidya et al., 2005a). This break in gene flow is thought to pre-date anthropogenic disturbance to the forests in the region.

Within northeastern India, mitochondrial and microsatellite DNA had showed different patterns of genetic differentiation between the North Bank and the Southwest-Southcentral Bank populations, as mentioned above. Vidya et al., (2005b) found that the population genetic differentiation based on mtDNA remained when females were analysed separately, but not when only males were compared across populations (Vidya et al., 2005b). This was explained by female philopatry, locational dispersal of males (in which males not only disperse from their natal groups, but also from their natal home ranges, see Vidya and Sukumar, 2005), and male-mediated gene flow across the Brahmaputra river that females with their young perhaps rarely negotiated. However, the Brahmaputra seemed to be an incomplete riverine barrier even to females, as there was an increasing similarity of mitochondrial haplotypes towards its upper reaches (Vidya et al., 2005b). The Brahmaputra 
is about $10 \mathrm{~km}$ wide on average and has also been a biogeographic barrier to other species, such as primates, pygmy hog, and hispid hare (Rodgers and Panwar, 1988).

\section{Concluding thoughts}

The distribution of haplotypes from elephants in India and Myanmar has proved to be crucial to testing the hypotheses of mtDNA introgression between species, allopatric divergence followed by subsequent admixture of the Sri Lankan and the mainland populations (Fernando et al., 2000), and of divergence and admixture of a Sunda and a mainland species and subsequent impaction of the southern Indian and Sri Lankan populations by trade (Fleischer et al., 2001), leading to the formation of the two mitochondrial clades. It appears that Pleistocene climatic oscillations have been paramount in shaping Asian elephant mtDNA phylogeography rather than human-assisted trade in elephants, and that introgression of mtDNA between known species of Elephas cannot explain the presence of the divergent clades. However, differentiation at nuclear genes remains to be examined in order to address the subspecies question (the Sumatran subspecies is the only one with molecular, albeit only mtDNA, and morphological support). Deraniyagala (1939) and Pocock (1943) mentioned the presence of two races within Sri Lanka and whether these correspond to the $\alpha$ and $\beta$ clades would make for interesting investigation. African elephants show cytonuclear dissociation, with mtDNA clades not corresponding to nuclear DNA lineages (Roca et al., 2001, 2005, Eggert et al., 2002, see Shetty and Vidya, 2011, Roca et al., 2015). Within India, congruent population genetic structuring across Asian elephant populations had been observed based on mitochondrial and microsatellite DNA (Vidya et al., 2005b). Fickel et al., (2007) had also found significant nuclear microsatellite differentiation between individuals of the two mtDNA clades in Thailand. This nuclear genetic differentiation was caused by males and there was no significant genetic differentiation based solely on females (Fickel et al., 2007), suggesting hybridization between divergent lineages resulting in lowered fitness of heterogametic (male) hybrids. Lei et al. (2012) examined 201 captive Asian elephants at X-linked genes (BGN and PHKA2) and a small number (23) of males at the Y-linked gene AMELY, but did not find any $\alpha$ or $\beta$ clade-specific lineage in these three genes, although the genes used were not sufficiently polymorphic. The findings of Fickel et al. (2007) are consistent with Vidya et al.'s (2009) proposed evolutionary history of the Asian elephant based on mtDNA, but whether this nuclear-mtDNA concordance exists across other populations remains to be seen.

Within India, genetic diversity seems to be largely typical, although mitochondrial diversity (but not microsatellite diversity) in southern India is low. While there was no evidence for a recent population bottleneck based on microsatellite DNA and an ancient population bottleneck was hypothesized (Vidya et al., 2005a), it would be useful to model mtDNA and microsatellite DNA diversity based on different population history scenarios in order to better understand the observed patterns of diversity. It appears from historical records that there should have been a considerable decline in elephants in southern India because of capture for use in war. Tipu Sultan, who ruled from the Mysore throne from the late $18^{\text {th }}$ century, is reported to have had 700 elephants in his army (see page 220, Sukumar, 2011), which were likely to have been captured from the Nilgiris population, based on proximity to Mysore. However, Sanderson (1879) maintains that population sizes had not declined and had, in fact, increased in southern India at the time of his writing. By his account (Sanderson, 1879), the number of elephants captured by the British was, for the most part, very small (about 2000 animals in 100 years, Sukumar, 2011, p. 230). The number 
of elephants has possibly declined markedly since the time of Sanderson, but this decline may be too recent to be discerned from the molecular markers used, given the long generation time of the species. Curiously, although elephants from Sri Lanka have traditionally been highly prized, resulting in large-scale captures from Sri Lanka, and hunting for sport wiped out several thousands of elephants from Sri Lanka (Sukumar, 2011, chapters 5,8), mtDNA diversity in Sri Lanka is still among the highest in Asia.

Modelling mitochondrial and microsatellite DNA diversity based on different population history scenarios would also be useful in understanding population genetic differentiation patterns within India, especially within southern India, where a break in gene flow across the Palghat Gap was found (Vidya et al., 2005a). This break in gene flow has subsequently spawned several studies to examine population genetic differentiation in other vertebrate species such as large mammals (Vidya et al., unpublished data), birds (Robin et al., 2010, 2015), and frogs (Bocxlaer et al., 2012; Nair et al., 2012). Similar multi-species studies within northeastern India and the adjacent regions of Myanmar to examine biogeographical barriers might be illuminating as well. For instance, two divergent mtDNA clades have been reported in the dhole (Cuon alpinus) also, and these clades were thought to have expanded from Pleistocene glacial refugia in southern India and Peninsular Malaysia or Indochina (Iyengar et al., 2005). It is unclear if the Brahmaputra or another barrier, possibly in Myanmar, kept the two clades separated in the Asian elephant (when the $\beta$ clade expanded to the Sunda region) and dhole. The Brahmaputra river was thought to have played an important role in separation between mtDNA clades in the rhesus macaque (Melnick et al., 1993).

In summary, sampling largely free-ranging individuals of the iconic Asian elephant from various populations in India has led to a better understanding of the evolutionary history of the species based on mtDNA, and has shed light on mitochondrial and nuclear genetic diversity and patterns of gene flow within the country. The latter have also paved the way for other studies, resulting in comparative phylogeography of a region, making the Asian elephant an 'umbrella species' (which when protected can afford protection to hundreds of other species that share its vast and varied range; Shrader-Frechette and McCoy, 1993) not just literally, but also figuratively in allowing new studies of other species to flourish.

\section{ACKNOWLEDGMenTS}

I thank Prof. Partha Majumder, Prof. D. Balasubramanian, and the Indian National Science Academy (INSA) for organizing the symposium on The Indian Heritage: a Genomic View, which stimulated me to reflect on this topic. I also thank JNCASR for support.

\section{BIBLIOGRAPHY}

Adams, J M and Faure, H (editors). Review and Atlas of Palaeovegetation: Preliminary Land Ecosystem Maps of the World Since the Last Glacial Maximum, Oak Ridge National Laboratory, Tennessee, 1997.

Bist, S S. An overview of elephant conservation in India, Indian Forester 128(2002):121-136.

Bocxlaer, I V; Biju, S D; Willaert, B; Giri, V B; Shouche, Y $\mathrm{S}$ and Bossuyt, F. Mountain-associated clade endemism in an ancient frog family (Nyctibatrachidae) on the Indian subcontinent, Molecular Phylogenetics and Evolution, 62(2012):839-847.

Deraniyagala, P E P. Some aspects of the Asiatic elephant in zoology and ethnography, Journal of the Royal Asiatic Society (Ceylon Branch), 34(1939):126-162.

Deraniyagala, P E P. Some Extinct Elephants, their Relatives and the Two Living Species, Government Press, Colombo, 1955.

Edgerton, F. The Elephant-lore of the Hindus: The Elephant Sport (Matanga-lila) of Nilakantha, Motilal Banarsidass, New Delhi, 1985 (reprinted).

Eggert, L S; Rasner, C A and Woodruff, D S. The evolution and phylogeography of the African elephant inferred 
from mitochondrial DNA sequence and nuclear microsatellite markers, Proceedings of the Royal Society of London B 269(2002):1993-2006.

Fernando, P; Pfrender, M, Encalada, S and Lande, R. Mitochondrial DNA variation, phylogeography and population structure of the Asian elephant, Heredity 84(2000):362-372.

Fernando, P; Vidya, T N C; Payne, J; Stuewe, M; Davison, G; Alfred, R J; Andau, P; Bosi, E; Kilbourn, A and Melnick, D J. DNA analysis indicates that Asian elephants are native to Borneo and are therefore a high priority for conservation, PloS Biology 1(2003):110115.

Fickel, J; Lieckfeldt, D; Ratanakorn, P and Pitra, C. Distribution of haplotypes and microsatellite alleles among Asian elephants (Elephas maximus) in Thailand, European Journal of Wildlife Research 53(2007):298-303.

Fleischer, R; Perry, E; Muralidharan, K; Stevens, E and Wemmer, C. Phylogeography of the Asian elephant (Elephas maximus) based on mitochondrial DNA, Evolution 55(2001):1882-1892.

Gathorne-Hardy, F J; Syaukani, Davies, R G; Eggleton, P and Jones, D T. Quaternary rainforest refugia in southeast Asia: using termites (Isoptera) as indicators. Biological Journal of the Linnaean Society, London 75(2002):453-466.

Hartl, G; Kurt, F; Hemmer, W and Nadlinger, R. Electrophoretic and chromosomal variation in captive Asian elephants (Elephas maximus), Zoo Biology 14(1995):87-95.

Hartl, G; Kurt, F; Tiedemann, R; Gmeiner, C; Nadlinger, $\mathrm{K}$; Mar, K U and Rubel, A. Population genetics and systematics of Asian elephants (Elephas maximus): a study based on sequence variation at the Cyt $b$ gene of PCR-amplified mitochondrial DNA from hair bulbs, Zeitschrift für Saugetierkunde 61(1996):285-294.

Iyengar, A; Babu, V N; Hedges, S; Venkataraman, A B; Maclean, N and Morin, PA. Phylogeography, genetic structure, and diversity in the dhole (Cuon alpinus), Molecular Ecology 14(2005):2281-2297.

Lei, R; Brenneman, R A; Schmitt, D L and Louis, Jr. E E. Genetic diversity in North American captive Asian elephants, Journal of Zoology 286(2012):38-47.

Lorimer, J. Elephants as companion species: the lively biogeographies of Asian elephant conservation in Sri Lanka, Transactions of the Institute of British Geographers NS 35(2010):491-506.
Maglio, V J. Origin and evolution of the Elephantidae, Transactions of the American Philosophical Society 63(1973):1-149.

Melnick, D J; Hoelzer, G A; Absher, R and Ashley, M V. mtDNA diversity in rhesus monkeys reveals overestimates of divergence time and paraphyly with neighboring species, Molecular Biology and Evolution 10(1993):282-295.

Nair, A; Gopalan, S V; George, S; Kumar, K S; Shikano, T and Merilä, J. Genetic variation and differentiation in Indirana beddomii frogs endemic to the Western Ghats biodiversity hotspot, Conservation Genetics 13(2012),1459-1467.

Nanda, A C. Upper Siwalik mammalian faunas of India and associated events, Journal of Asian Earth Sciences 21(2002):47-58.

Nozawa, K and Shotake, T. Genetic differentiation among local populations of Asian elephants, Zeitschrift für Zoologisce Systematik und Evolutionsforschung 28(1990):40-

Pocock, R I. Notes on the Asiatic Elephant (Elephas maximus). Annals and Magazine of Natural History 10(1943):273-280.

Robin, V V; Sinha, A and Ramakrishnan, U. Ancient geographical gaps and paleo-climate shape the phylogeography of an endemic bird in the sky islands of southern India, PloS One 5(2010):e13321.

Robin, V V, Vishnudas, C K, Gupta, P and Ramakrishnan, U. Deep and wide valleys drive nested phylogeographic patterns across a montane bird community, Proceedings of the Royal Society of London, Series B 282(2015):20150861.

Roca, A L; Georgiadis, N; Pecon-Slattery, J and O'Brien, S J. Genetic evidence for two species of elephant in Africa, Science 293(2001):1473-1477.

Roca, A L; Georgiadis, N and O'Brien, S J. Cytonuclear genomic dissociation in African elephant species, Nature Genetics 37(2005):96-100.

Roca, A L; Ishida, Y; Brandt, A L; Benjamin, N R; Zhao, K and Georgiadis, N J. Elephant natural history: a genomic perspective, Annual Review of Animal Biosciences 3(2015):139-167.

Rodgers, W A and Panwar, H S Planning a Wildlife Protected Area Network in India, Wildlife Institute of India, Dehra Dun, 1988 (two volumes).

Rohland, N; Malaspinas, A; Pollack, J L; Slatkin, M; Matheus, $\mathrm{P}$ and Hofreiter, M. Proboscidean 
mitogenomics: chronology and mode of elephant evolution using mastodon as outgroup, PLoS Biology 5(2007):1663-1671.

Ronquist, F. DIVA version 1.1, Uppsala University, 1996.

Ryder, O A. Species conservation and systematics: the dilemma of subspecies, Trends in Ecology and Evolution 1(1986):9-10.

Sanderson, G P. Thirteen Years Among the Wild Beasts of India: Their Haunts and Habits from Personal Observation; With an Account of the Modes of Capturing and Taming Elephants, $2^{\text {nd }}$ edition, Wm. H. Allen and Co., London, 1879.

Shetty, N R and Vidya, T N C. To split or not to split: the case of the African elephant, Current Science 100(2011):810-812.

Shrader-Frechette, K S and McCoy, E D. Method in Ecology: Strategies for Conservation, Cambridge University Press, Cambridge, 1993.

Shoshani, J and Eisenberg, J F. Elephas maximus, Mammalian Species 182(1982):1-8.

Sukumar, R. The Asian Elephant: Ecology and Management, Cambridge University Press, Cambridge, 1989.

Sukumar, R. The Living Elephants: Evolutionary Ecology, Behavior, and Conservation, Oxford University Press, New York, 2003.

Sukumar, R. The Story of Asia's Elephants, The Marg Foundation, Mumbai, 2011.

Sukumar, R and Santiapillai, C. Elephas maximus: status and distribution, in J Shoshani \& P Tassy (eds), The Proboscidea: Evolution and Palaeoecology of Elephants and their Relatives, Oxford University Press, Oxford, 1996, pp.327-331.

Sukumar, R; Ramesh, R; Pant, R and Rajagopalan, G. A C13 record of late quaternary climate change from peats in southern India, Nature 364(1993):703-705.

Templeton, A R. Nested clade analyses of phylogeographic data: testing hypotheses about gene flow and population history, Molecular Ecology 7(1998):381397.

Templeton, A R. Statistical phylogeography: methods of evaluating and minimizing inference errors, Molecular Ecology 13(2004):789-809.

Van den Bergh, G D; Sondaar, P Y; De Vos, J and Aziz, F. The proboscideans of the South-East Asian islands, in J Shoshani \& P Tassy (eds), The Proboscidea: Evolution and Palaeoecology of Elephants and their Relatives, Oxford University Press, Oxford, 1996, pp.240-248.

Vidya, T N C; Fernando, P; Melnick, D J and Sukumar, R. Population differentiation within and among Asian elephant (Elephas maximus) populations in southern India, Heredity 94(2005a):71-80.

Vidya, T N C; Fernando, P; Melnick, D J and Sukumar, R. Molecular genetic structure and conservation of Asian elephant (Elephas maximus) populations across India, Animal Conservation 8(2005b): 377-388.

Vidya, T N C; Varma, S; Dang, N X; Van Thanh, T and Sukumar, R. Minimum population size, genetic diversity, and social structure of the Asian elephant in Cat Tien National Park and its adjoining areas, Vietnam, based on molecular genetic analyses, Conservation Genetics 8 (2007): 1471-1478.

Vidya, T N C; Sukumar, R and Melnick, D J. A range-wide phylogeography of the Asian elephant (Elephas maximus) based on mitochondrial DNA, Proceedings of the Royal Society of London, Series B 276 (2009): 893-902.

Vidya, T N C; Sukumar, R and Melnick, D J. Correction: A range-wide phylogeography of the Asian elephant (Elephas maximus) based on mitochondrial DNA, Proceedings of the Royal Society of London, Series B 278 (2011): 798.

Yang, F and Zhang, L. Population genetic structure and population genetic diversity analysis based on mitochondrial DNA of Asian elephant (Elephas maximus) in China, Acta Theriologica Sinica 32 (2012): 90-100. 